\title{
Heparin Sodium Was Prepared from Pig Intestinal Mucosa by Dialysis and Spray Drying
}

\author{
Shunshun Shu*, Qian Mi*, Caixia Yang, Chonghuan Bao, Zhaoyang Wang, Jun Niü \\ C.P. Food (Xiangyang) Co. LTD., Xiangyang, China \\ Email: "1013360845@qq.com
}

How to cite this paper: Shu, S.S., Mi, Q., Yang, C.X., Bao, C.H., Wang, Z.Y. and Niu, J. (2018) Heparin Sodium Was Prepared from Pig Intestinal Mucosa by Dialysis and Spray Drying. Journal of Biosciences and Medicines, 6, 5-11.

https://doi.org/10.4236/jbm.2018.610002

Received: September 10, 2018

Accepted: October 7, 2018

Published: October 10, 2018

Copyright $\odot 2018$ by authors and Scientific Research Publishing Inc. This work is licensed under the Creative Commons Attribution International License (CC BY 4.0).

http://creativecommons.org/licenses/by/4.0/

\begin{abstract}
A method to extract crude heparin sodium from pig intestinal mucosa by dialysis and spray drying was established. The pig intestinal mucosa was treated in the following steps: enzymolysis, resin exchange adsorption-washing, elution, pressure filtration, dialysis, spray drying. Activity of the product was measured using a heparin anti-IIa factor assay kit. The yield of crude heparin obtained by this method was $2.79 \%$ higher than that of oven drying method; the production of $1 \mathrm{~kg}$ crude heparin sodium saved 43.4 pigs small intestine. The activity was $98.48 \pm 2.49 \mathrm{IU} / \mathrm{mg}(n=5), 15.18 \mathrm{IU} / \mathrm{mg}$ higher than that obtained by oven drying method. The product is pale white powder, attractive color and easy to dissolve.
\end{abstract}

\section{Keywords}

Heparin Sodium, Dialysis and Spray Drying, Oven Drying Method, The Production Process

\section{Introduction}

Heparin sodium is the sodium salt of heparin; it is a kind of natural mucopolysaccharide sulfate ester with complex structure extracted from biological materials. Its basic framework is a polysaccharide chain linked by a glycosylation bond between uronic acid and glucosamine. It generally forms a complex with proteins in animals [1]. The structure of heparin sodium is generally considered as Figure 1.

Heparin is a sulphated polysaccharide with a high affinity for antithrombin. When combined with heparin, antithrombin exhibits a fast acting and potent inhibitory activity for coagulant serine esterases: IXa, Xa and thrombin. Low Molecular Weight Heparin (LMWH), and heparin analogues inhibit more efficiently 


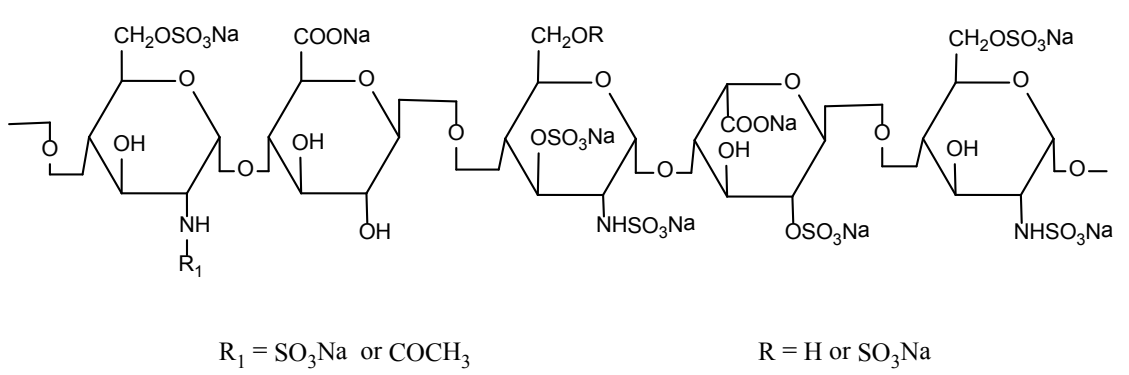

Figure 1. Heparin sodium structure formula.

Factor Xa than thrombin [2], whilst unfractionated heparin (UFH) inhibits efficiently thrombin and also the other serine esterases. Heparin sodium is widely distributed in the intestinal mucosa, lung and liver of mammals, and its molecular weight is generally between 3000 and $30,000 \mathrm{Da}$ [3]. Heparin sodium is of great medical and biological value [4]. It can prevent and treat arterial and venous thrombosis and pulmonary embolism. It is used as an anticoagulant in artificial heart and lung, peritoneal dialysis or hemodialysis [5] [6] [7].

In the 1980s, heparin research group of the department of biology of Si-Chuan University promoted the salt-hydrolysis process to extract heparin sodium from pigs' small intestine. Generally, it takes 3500 pigs' small intestine to produce 100 million units. In the 1990s, heparin was produced by enzymatic hydrolysis, which typically required 2500 small pigs to produce 100 million units. At present, these two processes are in use, and the most used process is enzymatic hydrolysis/salt hydrolysis-resin adsorption-elution-alcohol precipitation-dryinggrinding. After decades of optimization, 100 million units of heparin sodium can be extracted from the $1400-1700$ pigs' small intestine. The conventional process is simple, but it has many disadvantages, such as poor stability of the product, uneven color, great damage to the product, and a large amount of alcohol is needed to precipitate heparin [8]. Dialysis and spray drying provide the possibility to solve the above problems [9]. Therefore, the two steps of alcohol precipitation and drying in the production process of heparin sodium were improved by dialysis and spray drying in this article.

Anti-IIa assays are then the right methods for measuring the anti-thrombin activity of large heparin molecules [10]. The Heparin Anti-IIa method is a two-stage method based on the inhibition of a constant amount of Thrombin (IIa), by the tested heparin in presence of exogenous antithrombin, then hydrolysis of a Thrombin specific chromogenic substrate, by Thrombin in excess. pNA is then released from the substrate. The amount of pNA released is then a relation of the residual Thrombin activity. There is an inverse relationship between the concentration of heparin and color development, measured at $405 \mathrm{~nm}$.

\section{Materials and Methods}

\subsection{Materials and Reagents}

Pig intestinal mucosa (C.P. Food (Xiangyang) Co. LTD.), sodium chloride 
(Tianjin Beilian Fine Chemicals Development Co. LTD.), alkaline protease (Solarbio), sodium hydroxide (Chengdu Kelong Chemical Reagent Plant), absolute ethyl alcohol (Tianjin Yongda Chemical Reagent Co. LTD.), heparin sodium standard (Scientan), 2000 Da ultrafiltration membrane (Solarbio), heparin anti-IIa factor assay kit (Hyphen BioMed), D254 resin (The Dow Chemical Co.).

$R 1$ (Human Antithrombin, lyophilized vial containing about $1.25 \mathrm{IU} / \mathrm{mL}$ ), $R 2$ (Purified human Thrombin, mainly in the form, lyophilized vial containing about $120 \mathrm{IU} / \mathrm{mL}$ ), $R 3$ (Chromogenic substrate specific for Thrombin, lyophilized vial of about $6.25 \mu \mathrm{mol}$, in presence of mannitol), $R 4$ (Assay reaction buffer Tris $0.05 \mathrm{~mol} / \mathrm{L}, \mathrm{NaCl} 0.175 \mathrm{~mol} / \mathrm{L}$, EDTA $0.0075 \mathrm{~mol} / \mathrm{L}$, at $\mathrm{pH} 8.40$, containing Bovine Serum Albumin (BSA) at $0.2 \%$ and sodium azide as preservative), $R 5$ (Citric Acid at $20 \mathrm{~g} / \mathrm{L}$ ).

\subsection{Instrument and Equipment}

1/1000 balance (OHAUS), spray dryer (YAMATO), constant temperature drying oven (Sartorius), $200 \mu \mathrm{L}-1 \mathrm{~mL}$ pipettor (Sartorius), magnetic stirrer (IKA).

\subsection{Method}

\subsubsection{Heparin Sodium Extraction Steps}

1) The volume of fresh porcine intestinal mucosa was taken and added to the reaction pot. Added salt to the reaction pot to make the solution salt concentration of $5 \%$. The $\mathrm{pH}$ was adjusted to 8.5 - 9.5 with $5 \mathrm{~mol} / \mathrm{L}$ sodium hydroxide. The temperature was stirred up to $55^{\circ} \mathrm{C}$. The solution was hydrolyzed by stirring for $1 \mathrm{~h}$. If the salt concentration or $\mathrm{pH}$ value decreased, the salt and sodium hydroxide solution were added to adjust. Four over ten thousand of the protease was added, stirred and dissolved, kept for 2 hours, heated to $90^{\circ} \mathrm{C}$, and stopped heating. The decomposition solution was filtered with 120 mesh filter cloth while it was hot.

2) The filtrate was cooled to about $50^{\circ} \mathrm{C}$ and $\mathrm{pH}$ was adjusted to $8.5-9.5$. The treated resin was combined with the filtrate and the resin content was $6 \%$ of the filtrate weight. Stirred for 6 - 8 hours, stirring should not be too fast or too slow to make the resin up and down, otherwise the adsorption effect is poor. After adsorption, filtrate the resin with 120 mesh filter cloth.

3) The filtered resin was rinsed $2-3$ times with $38^{\circ} \mathrm{C}-42^{\circ} \mathrm{C}$ warm water of twice resin volume to remove fat and impurities adsorbed on the resin surface. The resin was then stirred and washed for 30 minutes with $5 \%$ salt solution of the same volume as the resin to remove low molecular weight heparin and some proteins that were not tightly bound to the resin. The resin was then filtered out with 120 mesh filter cloth.

4) For the first elution, the filtered resin was mixed with $22 \%$ salt solution in a volume ratio of 1:1, stirred and eluted for 2 hours, then the resin was filtered out to collect the filtrate. For the second elution, the concentration of salt solution was $18 \%$, stirred for 1 hour, the filtrate was combined with the first elution filtrate.

5) The collected filtrate passed through the membrane of $4.5 \mu \mathrm{m}$ to remove 
particulate impurities and precipitates, then collected the filtrate.

6) The filtrate was collected into the dialysis bag, dialyzed for 16 hours, changed water every 2 hours to remove the impurities with molecular weight less than 2000.

7) The obtained dialysate was spray dried and crude heparin sodium was obtained.

\subsubsection{Activity Determination of Crude Heparin Sodium}

Into the micro well or the plastic test tube, incubated at $37^{\circ} \mathrm{C}$, introduce:

1) $40 \mu \mathrm{L}$ reference material or tested sample and $40 \mu \mathrm{L} R 1$ was added to the micropore respectively, then mixed and incubated at $37^{\circ} \mathrm{C}$, for 2 minutes.

2) $40 \mu \mathrm{L} R 2$ was added to the micropore, mixed and incubated at $37^{\circ} \mathrm{C}$, for exactly 2 minutes.

3) $40 \mu \mathrm{L} R 3$ was added to the micropore, mixed and incubated at $37^{\circ} \mathrm{C}$, for exactly 1 minute.

4) $80 \mu \mathrm{L} R 5$ was added to the micropore, mixed and measured the absorbance at $405 \mathrm{~nm}$ against the corresponding blank.

\section{Result and Discussion}

\subsection{Effect of Dialysis and Spray Drying on the Appearance of Crude Heparin Sodium}

As shown in Figure 2, Figure 2(a) shows directly dried samples, while Figure 2(b) shows spray dried samples. The directly dried samples are plate shaped and brown in color. The spray-dried samples are powder and pale white in color. Compared with both of them, the latter is more beautiful in terms of traits and colors. And the step of grinding the samples of former into powder, the product obtained by spraying has a higher degree of powder and is more conductive to product dissolution.

\subsection{Effect of Dialysis and Spray Drying on the Yield of Crude Heparin Sodium}

The crude heparin sodium was extracted with $10 \mathrm{~L}$ intestinal mucosa by drying

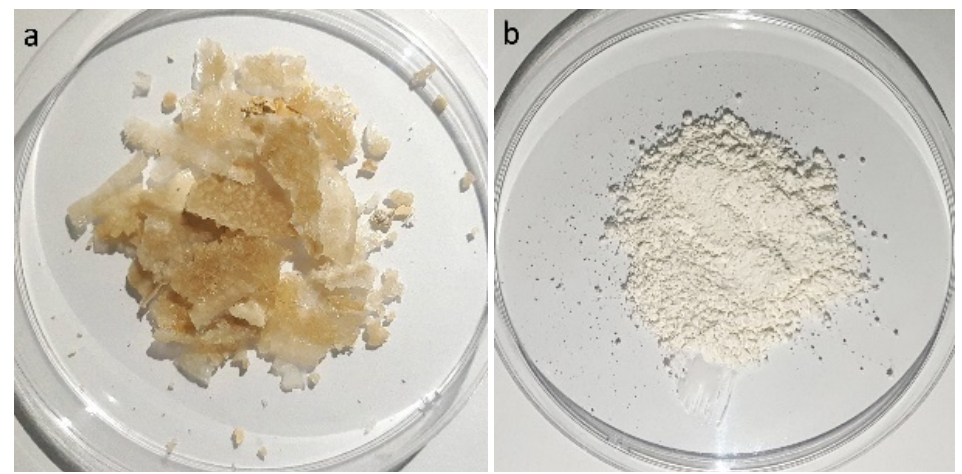

Figure 2. The appearance of crude heparin sodium obtained by directly drying and spraying. 
method and spray drying method, and the yield of crude heparin sodium was as shown in Table 1. Generally, 2 pig bismall intestines can produce $10 \mathrm{~L}$ intestinal mucosa fluid, and $1 \mathrm{~kg}$ crude heparin sodium obtained by spray drying method is less 43.4 pig small intestines than that obtained by drying method. This may be due to the fact that heparin sodium is dissolved in the eluent during alcohol precipitation without complete precipitation, while the crude heparin sodium is completely dried into a powder by spray drying.

\subsection{Effects of Dialysis and Spray Drying on the Potency of Crude Heparin Sodium}

The standard heparin sodium was diluted into a series of gradient, and the absorbance value was measured using the heparin anti-iia factor determination kit, and the standard curve was drawn as shown in Figure 3.

The absorbance of crude heparin sodium obtained by alcohol precipitation drying method and spray drying method was taken into the standard curve and the potency obtained is shown in Table 2. The titer of crude heparin sodium obtained by alcohol precipitation drying method was $83.3 \mathrm{IU} / \mathrm{mg}$. The relative standard deviation was $1.36 \%(n=5)$, and the titer of crude heparin sodium

Table 1. Effect of dialysis and spray drying on the yield of crude heparin sodium.

\begin{tabular}{ccccc}
\hline Technology & $\begin{array}{c}\text { Number of } \\
\text { small } \\
\text { intestine }\end{array}$ & $\begin{array}{c}\text { Volume of } \\
\text { intestinal mucosa } \\
\text { fluid/L }\end{array}$ & $\begin{array}{c}\text { Weight of crude } \\
\text { heparin } \\
\text { sodium/g }\end{array}$ & $\begin{array}{c}\text { Number of small intestine to } \\
\text { produce } 1 \text { kg crude heparin } \\
\text { sodium }\end{array}$ \\
\hline $\begin{array}{c}\text { Alcohol } \\
\text { sedimentation }\end{array}$ & 2 & 10 & $1.253 \pm 0.025$ & 1596.8 \\
Spray drying & 2 & 10 & $1.288 \pm 0.038$ & 1553.4 \\
\hline
\end{tabular}

Absorbance values/OD 405

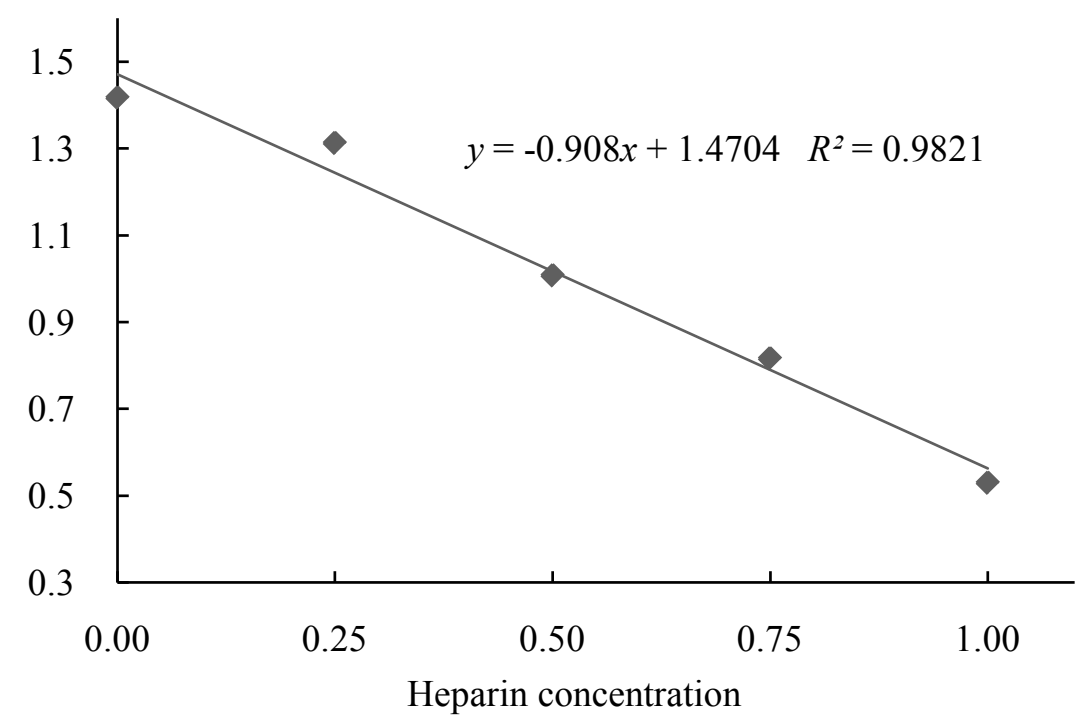

Figure 3. The potency of standard heparin sodium. 
Table 2. The titer of crude heparin sodium obtained by alcohol precipitation drying method and spray drying method.

\begin{tabular}{ccc}
\hline Method & Potency (IU/mg) & RSD/\% \\
\hline Alcohol precipitation drying method & 83.3 & 1.36 \\
Spray drying method & 98.48 & 2.53 \\
\hline
\end{tabular}

obtained by spray drying method was $98.48 \mathrm{IU} / \mathrm{mg}$. The relative standard deviation was $2.53 \%(n=5)$. The activity of the heparin sodium is 18.2 percentage points higher than that of alcohol precipitation drying method. This may be due to the removal of small molecular impurities with a molecular weight less than 2000 D during dialysis.

\section{Conclusion}

This method breaks down the traditional process of preparing crude heparin sodium. First, the collected eluent passed through the membrane of $4.5 \mu \mathrm{m}$. Then the filtrate was dialyzed. Finally, spray drying was carried out. The yield of crude heparin was $2.79 \%$ higher than that of oven drying method; the production of 1 $\mathrm{kg}$ crude heparin sodium saved 43.4 pigs small intestine. The activity of crude heparin sodium was $98.48 \pm 2.49 \mathrm{IU} / \mathrm{mg}(n=5), 15.18 \mathrm{IU} / \mathrm{mg}$ higher than that obtained by oven drying method. The product is pale white powder, attractive color and easy to dissolve.

\section{Conflicts of Interest}

The authors declare no conflicts of interest regarding the publication of this paper.

\section{References}

[1] Faham, S., Hileman, R.E., Fromm, J.R., Linhardt, R.J. and Rees, D.C. (1996) Heparin Structure and Interactions with Basic Fibroblast Growth Factor. Science (New York), 271, 1116-1120. https://doi.org/10.1126/science.271.5252.1116

[2] Buyue, Y., Misenemer, T.M. and Sheehan, J.P. (2012) Low Molecular Weight Heparin Inhibits Plasma Thrombin Generation via Direct Targeting of Factor IXa: Contribution of the Serpin-Independent Mechanism. Journal of Thrombosis and Haemostasis, 10, 2086-2098. https://doi.org/10.1111/j.1538-7836.2012.04892.x

[3] Mauri, L., Boccardi, G., Torri, G., Karfunkle, M., Macchi, E., Muzi, L., Keire, D. and Guerrini, M. (2017) Qualification of HSQC Methods for Quantitative Composition of Heparin and Low Molecular Weight Heparins. Journal of Pharmaceutical and Biomedical Analysis, 136, 92-105.

[4] Li, S.W., Feng, X., Xu, H. and Chen, K.J. (2018) Comparison on Anticoagulation and Antiplatelet Aggregation Effects of Puerarin with Heparin Sodium and Tirofiban Hydrochloride: An In Vitro Study. Chinese Journal of Integrative Medicine, 24, 103-108. https://doi.org/10.1007/s11655-017-2419-7

[5] Ma, L.Y., Liu, H. and Jiang, Z.W. (2012) Research Progress of Anti-Tumor Drugs Related to Heparin and Heparan Sulfate. Chinese Pharmacology Bulletin, 28, 1193-1196. 
[6] Caruana, R.J., Smith, M.C. and Clyne, D. (1991) Controlled Study of Heparin versus Epoprostenol Sodium (Prostacyclin) as the Sole Anticoagulant for Chronic Hemodialysis. Blood Purification, 9, 296-304. https://doi.org/10.1159/000170027

[7] Wu, D.M. (2010) Anticoagulation Therapy for Acute Deep Vein Thrombosis: Selection and Application of Heparin. Chinese Journal of Practical Surgery, 30, 1033-1034.

[8] Dong, H., Ding, L.X. and Luo, Z.L. (2014) Study on the Technology of High Efficiency Extraction of Heparin Sodium by Enzymatic Method Combined with Membrane Separation. Journal of Food Industry, 35, 158-160.

[9] Chen, Z. (2011) Improvement of Heparin Post-Treatment Process and Study of Low Molecular Weight Heparin Production Process. Huazhong University of Science and Technology, Wuhan.

[10] Mironoy, A.N., Goryachev, D.V. and Garvishina, E.V. (2015) Specific Anti-IIa Activity is a Key Indicator of Safety and Efficacy in Validation of Biosimilarity of Unfractioned Heparin Preparations. Bulletin of Experimental Biology and Medicine, 158, 450-452. https://doi.org/10.1007/s10517-015-2782-3 